\title{
A CRÍTICA PÓS-FUNDACIONALISTA: UM DEBATE EM CONSTRUÇÃO
}

\author{
The post-foundationalist criticism: a debate under construction
}

\author{
Caroline Bianca Graeff' \\ Kamila Nascimento ${ }^{2}$ \\ Marcelo de Souza Marques ${ }^{3}$
}

\begin{abstract}
Resumo
0 debate pós-fundacionalista emerge como uma potente discussão ao trazer à tona críticas relevantes às abordagens teóricas existencial-fundacionalistas. Tal debate nos conduz a refletir sobre a compreensão do social a partir de uma visão plural e contingente, que rompe com a forma de se pensar a realidade baseada em certezas e em uma ordem definitiva. Nesse contexto, este artigo objetiva apresentar alguns elementos centrais da crítica pós-fundacionalista, evidenciando aspectos que envolvem seu surgimento, suas bases filosóficas, assim como a distinção entre fundacionalismo, anti-fundacionalismo e pósfundacionalismo. Para tanto, aborda-se autores-chave como Heidegger, Derrida e Marchart. Pretendemos, assim, contribuir para clarear alguns aspectos que envolvem esta abordagem, oferecendo ao leitor uma apresentação concisa, mas consistente, das linhas gerais sobre as quais o debate se desenvolve no intuito de propiciar reflexões e questionamentos para um aprofundamento acerca desta perspectiva epistemológica.
\end{abstract}

Palavras-chave: Fundacionalismo; anti-fundacionalismo; pós-fundacionalismo; epistemologia.

\begin{abstract}
The post-foundationalist debate emerges as a potent discussion by bringing to the fore relevant criticism against existential-foundationalist theoretical approaches. This debate leads us to reflect on an understanding of the social from a plural and contingent view, which breaks with a way of thinking about a reality based on certainties and a definitive order. In this context, this article presents some central elements of post-foundational criticism, evidencing what involves its emergence, its philosophical bases, as well as a distinction between foundationalism, anti-foundationalism and post-foundationalism. For this, we approach key authors such as Heidegger, Derrida and Marchart. We intend, therefore, to clarify some that involve this approach, offering the reader a concise but consistent presentation of the general

\footnotetext{
1 Graduada em Direito pela Anhaguera Educacional de Pelotas e mestre em Ciência Política pela Universidade Federal de Pelotas (UFPel). Doutoranda em Ciência Politica na Universidade Federal de Pelotas. Email: carolinegraeff@gmail.com. Cidade: Pelotas, Rio Grande do Sul.

2 Graduada em Ciências Sociais pela Universidade Federal de Pelotas (UFPel). Mestre e doutora em Ciência Política pela Universidade Federal. Professora no Centro Universitário Unifametro. Email: kamiladonascimento@gmail.com. Cidade: Fortaleza, Ceará.

${ }^{3}$ Graduado em Ciências Sociais pela Universidade Federal do Espírio Santo (UFES) e mestre em Ciência Política pela Universidade Federal de Pelotas (UFPel). Doutorando em Sociologia na Universidade Federal do Rio Grande do Sul (UFRGS) e integrante do Grupo de Pesquisa Associativismo, Contestação e Engajamento (GPACE). E-mail: marcelo.marques.cso@gmail.com. Cidade: Porto Alegre, Rio Grande do Sul.
} 
guidelines on how the debate develops to provide reflections and questions to deepen the epistemological perspective.

Keywords: Fundamentalism; Anti-nationalism; Post-foundationalism; Epistemology.

\section{Introdução}

O debate sobre a crítica pós-fundacionalista é um tema ainda em construção. Apresentar o pós-fundacionalismo em uma conceituação única reduziria seu alcance e subverteria aspectos distintos que abarcam a discussão. Mas seu contrário, abarcar todas as nuances relacionadas a esta vertente teórica, seria impossivel em um espaço tão limitado. Assim, consideramos importante trazer neste artigo algumas características centrais a partir de uma visão mais geral acerca desta perspectiva teórico-filosófica sem, contudo, pretender esgotar o debate sobre o tema e tampouco compreender todas as possiveis dimensões que a teoria pode abarcar.

De forma mais especifica, temos como objetivo apresentar alguns elementos centrais da crítica pós-fundacionalista, evidenciando aspectos que envolvem seu surgimento, suas bases filosóficas e a distinção entre fundacionalismo, anti-fundacionalismo e pós-fundacionalismo. O que pretendemos é contribuir para evidenciar aspectos centrais da vertente pósfundacionalista, permitindo ao leitor adentrar esse universo e ser conduzido a refletir sobre a compreensão do mundo e do social a partir de uma visão plural e contingente, que rompa com a forma de se pensar a realidade baseada em certezas e em uma ordem definitiva.

Para uma melhor apresentação das reflexões, subdividimos o trabalho em duas partes. Na primeira, trataremos da perspectiva fundacionalista, demonstrando como esta abordagem epistemológica estrutura e valida a produção de conhecimento. Evidenciamos que o fundacionalismo busca em uma crença ${ }^{4}$ básica, última e autojustificável a legitimidade e o fundamento para outras crenças ou conhecimentos; dessa forma, todo o conhecimento científico estaria edificado sobre um conhecimento último ou um fundamento que garantiria e justificaria o conhecimento posterior. Na segunda parte,

\footnotetext{
4 No âmbito deste artigo, importante salientar que utilizarmos a palavra "crença" como sinônimo de convicção ou certeza. Crença está relacionada às expressões "fundamento último ou basilar", "conhecimento último", "centro fundante" ou ainda "principio fundante".
} 
destacaremos a crítica pós- fundacionalista, distinguindo-a da perspectiva anti-fundacionalista. Ao contrário da abordagem fundacionalista, a crítica pós-fundacionalista destaca que o conhecimento não se justifica a partir de uma crença básica, mas sim a partir da ideia de ausência de um fundamento último, absoluto. Em outras palavras, a crítica pós-fundacionalista desloca a ideia de fundamento último e pensa a partir da aceitação de fundamentos contingentes, precários e parciais, o que também a distingue das leituras antifundacionalistas, as quais buscam sustentar a negação da fundamentação.

\section{Fundacionalismo}

O fundacionalismo representa uma tradição epistêmica extensa, abrangendo diferentes orientações, o que torna impossível serem apresentadas em um único trabalho. Diante disso, para nosso intento, limitamo-nos a indicar que o ponto comum entre diferentes abordagens fundacionalistas é a crença fundamental da existência de um centro que orienta, equilibra e organiza a estrutura: um fundamento último. Em outras palavras, essa tradição sustenta que há um fundamento que define e que possibilita sua totalização estrutural. Este centro, como destaca Derrida (2002), já foi designado por muitos nomes (essência, existência, substância, sujeito, transcedentalidade, consciência, Deus, homem e etc.), mas todos eles nomearam uma presença de algo que origina e fundamenta o jogo estrutural.

Uma retomada no tempo do pensamento fundacional nos levaria até o ponto em que registros históricos já nem estariam disponíveis. Na tradição ocidental, sua fundação é geralmente aceita como tendo a igual idade da história da metafísica. Para Derrida, a história da metafísica pode, inclusive, ser pensada enquanto história das sucessivas substituições da presença do fundamento (DERRIDA, 2002).

Somente para exemplificar a origem do pensamento fundacional, podemos retomar o pensamento dos pré-socráticos, autores que se dedicaram a refletir sobre a origem de todas as coisas, numa transição da tradição mitológica para a filosófica. Essa transição é fundamental para a compreensão dos elementos que servirão para compor a tradição filosófica original. De acordo com Pessanha (1978), no pensamento mitológico os deuses homéricos 
eram animados por sentimentos e paixões humanas, o que deixava o universo à mercê de comportamentos passionais e a arbitrios capazes de alterar seu curso normal. Isso limitava o índice de racionalização e é em sua oposição que uma formulação teórica, filosófica ou científica exigirá o pressuposto de uma legalidade universal, exercida de forma impessoal e lógica. Então, abolindo-se a atuação de vontades divinas divergentes, chegar-se-á a um divino neutro imparcial: a divina arché $e^{5}$ das cosmogonias dos primeiros filósofos.

É a partir do século VI a.C que desponta nas colônias da Ásia Menor uma nova mentalidade, fruto da progressiva valorização da "medida humana" (e às vezes também em oposição à ela) e da laicização da cultura, que coordenou racionalmente os dados da experiência sensivel, buscando integrálos numa visão compreensiva e globalizadora com a finalidade de reduzir a multiplicidade e perceber a unidade exigida pela razão. Dentro desse espírito surgiram, na Jônia, as primeiras concepções científicas e filosóficas da cultura ocidental, propostas por pensadores da escola de Mileto, que propuseram sucessivas versões de uma física e de uma cosmologia constituídas em termos qualitativos (PESSANHA, 1978).

O que esses pensadores buscavam era encontrar no mundo físico uma origem alternativa ou fonte originária para todas as coisas, ou dito em outras palavras, uma explicação do universo através da "causa material". Pensar numa origem é remeter necessariamente a algo como uma estrutura organizadora da vida social, um centro fundante. Os estudiosos gregos buscaram no mundo concreto explicações para o fenômeno da existência de tudo. O ar, a água e outras inúmeras propriedades conhecidas foram testadas para assumir a tarefa de centro, o qual definiria, através de sua existência, como se dariam todas as relações, organizando, regulando, orientando os indivíduos, estruturando-os, portanto.

Desde então, vários centros foram propostos ao longo da história da metafísica e mesmo adentrando a ciência moderna. No entanto, não devemos entender "vários centros" como uma multiplicidade de centros aceitos

\footnotetext{
5 Esta divina arché significa a verdade absoluta, o princípio basilar de todas as coisas, um princípio originário que seria infinito e ilimitado, permanente e imutável. Assim, a divina arché fundante do universo correspondeu à busca desses primeiros filósofos.
} 
concomitantemente como fundamentos, mas apenas como uma disputa entre vários centros pela ideia de um efetivo centro como tal.

Dessa forma, o fundamentalismo (ou fundacionalismo) como uma perspectiva filosófica e epistemológica surge da busca por uma explicação que sustente e fundamente a origem das coisas, a existência do universo ou, em outras palavras, que permita compreender o centro que sustenta o social e todas as coisas. Assim, pode ser reconhecido como uma perspectiva epistemológica que busca um fundamento último a partir do qual todas as demais coisas e conhecimentos estariam sustentados.

Este princípio básico, ou centro fundante, está instituído em si mesmo e por esta razão não necessita de nenhum tipo de justificativa, servindo de argumento ou legitimação para a existência dos conhecimentos dele derivados. Assim, a crença básica (fundamento ou princípio) é autojustificada e arbitrária, e é a partir dela que serão desenvolvidos e legitimados os demais conhecimentos. Como destaca Ketzer (2011, p. 112), “a justificação epistêmica é baseada em provas, garantias, indícios para crer (...). Uma crença justificada é uma crença na qual estamos assegurados epistemicamente a crer e a qual temos o direito de defender".

Assim, todo o conhecimento científico ocidental, originado da filosofia metafísica, estaria edificado sobre uma crença em um fundamento último que garantiria e justificaria o conhecimento posterior. Desta forma, o saber seria justificado através da remissão a estes princípios básicos válidos. Esta remissão, ou regresso, significa, em última análise, que sempre haverá um conhecimento anterior que justificará o conhecimento posteriormente desenvolvido e, da mesma forma, este conhecimento dependerá de uma crença anterior a ela que a justifique. Assim, se a crença A está justificada pela crença $\mathrm{B}$, a crença $\mathrm{B}$ depende da justificação obtida na crença $\mathrm{C}$ e, igualmente, a crença $C$ se justifica na crença $D$, seguindo, assim, de forma infinita.

A inferência infinita de justificações suscita a crítica de que a partir dela o conhecimento nunca será por fim justificado, pois será sempre remetido a uma nova crença. A regressão infinita seria, segundo seus críticos, insustentável teoricamente, "já que, por mais longa que seja a cadeia das razões e por mais fortes que sejam seus elos, ela não estará efetivamente 
ancorada em lugar algum" (BURDZINSKI, 2007, p. 109) e, assim, não haverá justificação apta a produzir conhecimento.

Diante disso, duas alternativas são possiveis para resolver o problema do regresso infinito. Como destaca Burdzinski (2007, p. 109), a primeira conduz a "um modelo circular da estrutura de justificação epistêmica", modelo que não se sustenta frente à impossibilidade de uma crença ser justificada por outra para a qual serviu de justificação (A justifica $B, B$ justifica $C$ e $C$ justifica A). Já a segunda alternativa seria suspender o regresso em algum ponto. Essa suspensão poderia ser feita de dois modos: de forma injustificada ou arbitrária, o que seria um procedimento "epistemologicamente insustentável, pois firma compromisso com a singular tese de que a justificação última é injustificada"; ou, ainda, "detida desde a suposição de que o elo último da cadeia é de natureza diversa daquela dos demais" (BURDZINSKI, 2007, p. 109), ideia que sintetiza a teoria fundacionalista.

Para esta última perspectiva, a fundacionalista, o elo final deverá ser justificado de forma diferente das demais crenças, de modo a evitar a continuação do regresso. De forma básica, conforme mencionado anteriormente, o fundacionalismo admite que esta crença última seja autojustificável, sendo possivel auferí-la de uma experiência sensorial ou empírica, ou seja, este conhecimento será construído "diretamente da percepção, da introspecção, da memória ou da razão" não sendo, desta forma, necessária a sua justificação por outras crenças (FIANCO, 2011, p. 38) ${ }^{6}$.

Assim, o fundacionalismo resolve o problema da remissão infinita afirmando a existência de uma crença básica que não necessitaria de justificação e, desta forma, finalizaria a cadeia do regresso. É o que também destaca Burdzinski:

Em termos metafóricos, o que o fundacionista nos pede para conceber é algo como o elo primeiro de uma corrente, um elo que fixa esta em uma superficie sólida e que faz com que ela cumpra a função de ligar e dar sustentação para a qual presumivelmente foi projetada. Tal elo não é nem pode ser da mesma natureza dos demais. Elos ordinários, com efeito, ligam-se uns aos outros (têm, de um lado e de outro, algo

\footnotetext{
6 Não adentraremos nos debates específicos que agrupam as distinções entre fundacionalismo forte e fraco, nem sobre fundacionalismo internalista ou externalista, por entendermos não consubstanciar o norte deste artigo e configurarem temas que possuem a necessidade de uma abordagem mais profunda, a qual não caberia no âmbito deste trabalho. Para mais informações sobre estes assuntos, ver Burdzinski (2007) e Fianco (2011).
} 
da mesma natureza que eles próprios); o elo primeiro que buscamos, porém, deve fundir-se àquilo que lhe dá sustentação. De um lado, é um elo da cadeia; de outro, não é mais elo, mas sim alguma coisa diferente, é base, fundação, alicerce. Ele é um primeiro elo que já não seja inteiramente elo, é uma criatura de dois mundos (BURDZINSKI, 2007, p. 113).

Portanto, o fundacionalismo expressa uma perspectiva epistemológica que se baseia no conceito de crenças básicas ou fundamentos para a construção do conhecimento. Dessa forma, o conhecimento deve ser concebido como uma estrutura que se ergue a partir de fundamentos certos e seguros, de uma estrutura básica, central e imutável.

As crenças fundamentais são responsáveis por deter o regresso infinito, servindo como base para todo o restante de crenças que justificam aquilo que afirmamos conhecer, assim, as crenças justificam-se inferencialmente umas às outras, mas existem crenças básicas, que são não inferencialmente justificadas. Estas não devem a sua justificação a outras crenças (KETZER, 2011, p.113).

Apesar da origem destacada acima do fundacionalismo como campo do conhecimento filosófico e epistemológico, a referida abordagem também influenciou outros campos do conhecimento, senão todos. Para a finalidade deste estudo, como uma contribuição para o campo social, temos de destacar a entrada dessa forma de pensar através do campo da linguística que mais tarde motivaria sua utilização nas ciência sociais.

A principal fonte do fundacionalismo nas ciências sociais foi $o$ estruturalismo linguístico, especialmente relacionado a Ferdinand de Saussure, que se pretendia como uma abordagem "científica" sobre o estudo da língua. O autor propunha uma distinção que seria essencial na aplicação do estruturalismo nas ciências sociais entre fala e língua, sendo o segundo o sistema formal que governa o primeiro. Outra característica que distingue a linguística de Saussure é a ênfase na "autonomia do sistema [linguístico], visto como um todo que compreende e organiza elementos fônicos e semânticos não diretamente acessiveis à experiência sensória” (PETERS, 2000, p.20).

Entretanto, o nascer do estruturalismo e sua divulgação tiveram como fator decisivo sua adoção e desenvolvimento por outra importante figura: Roman Jakobson. De fato, foi esse autor que cunhou o próprio termo estruturalismo, em 1929, para se referir à abordagem de investigação científica, cuja tarefa básica consistiria em revelar as leis internas de um 
sistema determinado. Após um encontro com ele no início dos anos 1940, na New School for Social Science Research, em Nova York, Lévi-Strauss decidiu adotar os princípios da linguística estrutural em seu trabalho na antropologia, marcando o início da adoção do estruturalismo nas ciências sociais (PETERS, 2000).

Claude Lévi-Strauss popularizou o estruturalismo de Ferdinand de Saussure e Roman Jakobson, aplicando os principios da linguística estrutural ao estudo das estruturas do parentesco (1949) e, sobretudo, à análise dos mitos (1955). Como previamente exposto, a ideia básica de Saussure era de que a língua se constituía em um sistema autônomo, no qual os códigos e as regras precedem e determinam as práticas (a fala). Dessa forma, enquanto a fala era um ato individual e podia ser atualizada pelo individuo, a lingua tendia a conservar-se inalterada. Essa é a mesma lógica que Lévi-Strauss transpôs para a antropologia estrutural (RODRIGUES, 2010).

Importante destacar que, apesar da origem em Lévi-Strauss, o estruturalismo nas ciências sociais foi bastante proficuo compreendendo diversas vertentes. Podendo ser definido de muitas maneiras, tais como uma teoria, uma postura intelectual, um método de investigação científica, entre outras, o estruturalismo comporta diferentes pensadores e de gerações distintas, onde cada "um encontra problemas, métodos, soluções que têm relações de analogia, como que participando de um ar livre do tempo, de um espírito do tempo, mas que se mede com as descobertas e criações singulares" (DELEUZE, 1972, p. 239).

Para fins deste artigo, entretanto, é essencial reter que os estruturalistas concordam entre si com a ideia de que haveria no social determinadas estruturas fundamentais que possuem a capacidade de determinar a própria convivência humana. Principalmente, acreditam que os sujeitos são definidos de fora para dentro através do inconsciente e da linguagem. Assim, o estruturalismo comunica-se com a perspectiva fundacionalista, ambas procurando evidenciar a existência de fundamentos epistemológicos e identificar estruturas universais comuns a todos os seres humanos, suas culturas e civilizações, estruturas as quais subjulgariam o agir do indivíduo que seria conduzido a ação pelas estruturas fundantes. 
Isto significa posicionar-se contrariamente a toda filosofia do cogito: "Uma perspectiva universalista da razão e, portanto, do humano e do sujeito, é totalmente rechaçada pelo estruturalismo, desde sua gênese. Para o estruturalismo, a subjetividade da ação, oriunda da subjetividade do indivíduo que atribui significados, sentido às coisas, não existe" (RODRIGUES, 2010, p.166). Da perspectiva estrutural, os sujeitos estão invariavelmente subjugados pelas estruturas. "Aquilo que é visto ou pensado, seja no campo individual, como afirmaram Freud e Lacan, seja no campo social, como afirmavam Marx e Althusser, está inexoravelmente conduzido por um (ou mais) sistema de correlação estrutural" (RODRIGUES, 2010, p.166).

Contrapõem-se, desse modo, ao paradigma humanista, por exemplo, em que o homem surge como o próprio centro da existência humana. Para esta corrente, o sujeito autocentrado faz-se a si mesmo e constrói o mundo a partir de suas necessidades, tendo liberdade para criar. No estruturalismo, por outro lado, o sujeito está subjugado pelas estruturas. Esta característica é a idiossincrasia que fará o sucesso do estruturalismo, pois possibilitou excluir o sujeito, "demasiado aleatório, e a história, demasiado contingente, em proveito de um modelo tão rigoroso quanto às ciências da natureza" (DOSSE, 1993, p.193).

O estruturalismo, pode-se dizer, foi o ápice das teorias fundacionais relacionadas às ciências sociais em tempos recentes. Entretanto, o fundacionalismo, como capacidade de crença última e absoluta, entra em crise a partir do início do século $\mathrm{XX}$, com as críticas à metafísica e ao existencialismo (MENDONÇA; RODRIGUES, 2014). A defesa do fundamento básico dá lugar à instituição de um conhecimento que não está justificado em si mesmo, mas sim em uma pluralidade de crenças e saberes que se sobrepõem e se articulam, não havendo verdades absolutas nem fundamentos últimos que legitimam e edificam os demais, estabelecendo, assim, as bases do que surgirá ao debate como pensamento pós-fundacional, objeto do próximo tópico.

\section{Crítica Pós-fundacionalista}

A crítica pós-fundacionalista pode ser entendida, conforme Mendonça 
e Rodrigues (2014), como uma perspectiva filosófica que surge nos debates teórico-epistemológicos a partir de meados do século XX. Nesse contexto, como destacam os autores, buscava-se problematizar, a partir de diferentes abordagens teóricas, concepções já sedimentadas no campo científico, como o positivismo lógico, a metafísica e o estruturalismo clássico ${ }^{7}$. De uma forma mais geral, diferentes autores relacionados a essa crítica buscam fazer aparecer a estruturalidade da estrutura, evidenciando seu caráter contingencial, e colocar o centro para jogar o jogo que ele abre.

Para avançarmos sobre a crítica pós-fundacionalista, precisamos, antes, operar uma distinção fundamental da crítica anti-fundacionalista. Como destaca Marchart (2009), a crítica anti-fundacionalista significa uma negação final da noção de fundamento, isto é, a simples invalidação de toda possibilidade de estabelecimento de fundamentos ao jogo estrutural. Contrariamente a essa perspectiva, a crítica pós-fundacionalista não tem por objetivo uma completa negação da ideia de fundamento, mas "debilitar seu status ontológico" (MARCHART, 2009, p.15) ${ }^{8}$, isto é, reduzir sua centralidade e imobilidade estrutural e, por conseguinte, colocar em questão a possibilidade de determinação de um fundamento último.

A crítica pós-fundacionalista, ao contrário da anti-fundacionalista, não nega a ideia de fundamento da estrutura, mas busca subverter as premissas das perspectivas fundacionalistas sem cair na mera inversão da noção, simplesmente negando qualquer possibilidade de estabelecimento de fundamentos. Assim, não estamos distantes nem da aceitação de fundamentos finais, nem da impossibilidade dos mesmos. O que temos são, para usar um termo de Butler (1992), fundamentos contingentes, cuja ideia, como temos apresentado, busca evidenciar certa debilidade do status de fundamento.

\footnotetext{
7 É de fundamental importância ter claro que existem diferentes abordagens teóricas pósfundacionalistas e pós-estruturalistas (PETERS, 2000; WILLIAMS, 2016; RODRIGUES; MENDONÇA, 2014; MARCHART, 2009). Com isso, queremos dizer que não se trata de uma "escola" e sim de um movimento filosófico que emerge em meados do século XX e se desenvolve com diferentes autores e perspectivas. Para um aprofundamento acerca das perspectivas teóricas do positivismo lógico, da metafísica e do estruturalismo clássico, ver Mendonça e Rodrigues (2014), Capra (1972), Tamayo (2003), Hessen (2000), Peters (2000), Williams (2016).

8 Todas as citações de Marchart (2009) foram livremente traduzidas pelos autores.
} 
A noção de contingência ${ }^{9}$, profundamente enraizada na crítica pósfundacionalista, coloca-nos diante da recusa de concepções que aceitam fundamentos normativos estáveis e, por conseguinte, leva-nos a aceitar o caráter precário, parcial, histórico, instável dos fundamentos em substituição à ideia de fundamento último (BUTLER; 1992; MARCHART, 2009; MENDONÇA; LINHARES; BARROS, 2016).

Em sintese, a base comum da crítica pós-fundacionalista é a crítica contra a existência de um fundamento final, pois este negaria a contingência do mundo e a possibilidade de mudanças. É preciso, contudo, destacar que, apesar do ponto de contato comum, os pós-fundacionalistas não podem ser caracterizados como um grupo homogêneo e inclusive partem de diferentes ideias para chegarem à conclusão da ausência de um centro ou essência. $O$ caminho que percorremos neste artigo é aquele iniciado por Heidegger e continuado por Derrida e seguidores que desenvolvem as noções de ausência/falta e de fundamentos contingentes ou fundamentos ausentes ${ }^{10}$, buscando evidenciar o enfraquecimento ontológico dos fundamentos existentes ${ }^{11}$.

A discussão sobre o fundamento em Heidegger está ligada de forma inescapável à discussão sobre o Ser. Isto porque, segundo a leitura heideggeriana, por toda a história tradicional do fundamento, jamais se discutiu sobre o fundamento enquanto tal, mas somente sobre os entes. É nesse sentido que o autor argumenta que "o principio fundamental do fundamento representa decerto o fundamento numa perspectiva essencial, mas se expressa nessa perspectiva sobre o ente e não sobre o fundamento" (HEIDEGGER, 1999, p.72). É por esta razão que, segundo Mendonça, Linhares e Barros (2016, p. 171), o projeto de Heidegger prontifica-se em "destruir essa entificação histórica do ser e, por outro lado, dar lugar a um

\footnotetext{
9 Segundo Abbagnano (2007, p. 200), contingente, construção filosófica de influência árabe, é tudo que é, mas que poderia não vir a ser; é aquilo que é "não-determinado", nem por isso impossivel: "Desse ponto de vista, enquanto o possível não só não é necessário em si, mas tampouco é necessariamente determinado a ser".

10 A ideia de fundamentos contingentes pode ser tomada como sinônimo de fundamentos ausentes, é o que nos mostra Marchart (2009, p. 50): "A 'contingência' como conceito não é senão o nome dado ao fundamento ausente desde o ponto de vista do discurso teórico e sobre a base do vocabulário tradicional e da reserva conceitual acessivel dentro da teoria e da metafísica".

11 Essa discussão também está presente em Mendonça, Linhares e Barros (2016).
} 
pensamento que não encontre uma identidade (que não existe) no ser, mas que reflita sobre ele sem incorrer novamente em sua entificação".

Para explicar a perspectiva tradicional e a mudança proposta por ele, Heidegger lança mão de dois versos encontrados no livro de poesia espiritual de Angelus Silesius e discorre longamente sobre eles, mostrando suas inconsistências: "A rosa é sem porquê; ela floresce, porque ela floresce, Ela não repara si própria, não pergunta, se a vemos” (HEIDEGGER, 1999, p.59).

O "porquê" e o "porque" marcam coisas completamente distintas, ainda que ambas se relacionem à rosa. "O 'sem porquê' diz, falando a grosso modo: a rosa não tem qualquer fundamento. Em contrapartida diz o 'porque' no mesmo verso, ouvido imperfeitamente: a rosa tem um fundamento" (HEIDEGGER, 1999, p.67). Heidegger, por conseguinte, traduz esse pensamento na forma: a rosa é certamente sem porquê, não é contudo sem fundamento:

\begin{abstract}
O "porquê" e o porque falam de uma relação respectivamente diferente do nosso representar para com fundamento. No "porquê" seguimos interrogativamente o fundamento. No "porque" vamos buscar, respondendo, o fundamento. Em consequência, nós trazemos, assim parece, no "porque" o fundamento até uma relação mais próxima conosco, enquanto no "porquê" nós afastamos, por assim dizer, o fundamento de nós. Observadas exatamente, as coisas são, contudo, ao contrário. No "porquê", pomos o fundamento, para que ele nos dê uma satisfação e responda. No "porque" soltamos, pelo contrário, a nossa representação em direção ao fundamento e à coisa que por ele é fundamentada. No "porque" entregamo-nos à coisa fundamentada; nós entregamos a coisa assim própria e ao modo, como o fundamento, fundamentando-a, deixa simplesmente ser a coisa, que ela é (HEIDEGGER, 1999, p.68).
\end{abstract}

A rosa é sem porquê e contudo não sem porque. Apresenta-se, então, uma contradição, isto é, uma simultânea afirmação e negação da mesma, em outras palavras, a afirmação e a negação do fundamento. A rosa floresce porque ela floresce e não precisa para isso de prestar atenção em si própria (HEIDEGGER, 1999); não que se negue que o florescer da rosa tem um fundamento, o que se nega é que haja "substância ou essência fora do ser que determine o seu fundamento" (MENDONÇA; LINHARES; BARROS, 2016, p.173).

É por esta razão que Heidegger, em oposição aos anti-fundacionalistas, não abre mão do fundamento, ele não nega a metafísica. O Ser não pode ter 
um fundamento que o funde de fora dele e além dele mesmo. Não existe um fundamento que comande "de fora" o Ser, tal como nas ontologias históricas que o entificaram. Existe, contudo, um fundamento que está no próprio Ser, aquele representado por Heidegger como um abismo (ab-grund). Abismo porque o fundamento do Ser não se apoia em nada que esteja fora dele, apoiase em si próprio, logo, não se apoia em nada, é abissal: "Se o fundamento não está fora, mas no ser, se o ser é essencialmente fundamento, ergo o ser é 'semfundamento', é 'abismo', ou o abismo é o fundamento e o fundamento é o abismo" (MENDONÇA; LINHARES; BARROS, 2016, p.172).

É na noção de “abismo" (ab-grund) que encontramos em Heidegger, e em diferentes leituras pós-fundacionalistas que partem do autor, a ideia de fundamentos ausentes em prol do argumento sobre a impossibilidade de um fundamento último:

Este argumento se deve tanto a Martin Heidegger que não seria
exagerado considera-lo um dos principais "fundadores" do pós-
fundacionalismo. Para Heidegger, a ausência do fundamento é própria
da natureza de um abismo, ou seja, de um fundamento sem
fundamento, de um fundamento sem fundo. Desse modo, a
fundação, todavia, acontece: a "função" do fundamento enquanto
fundamento não desaparece por completo. Não obstante, acontece
unicamente na medida em que passa através de um "a-bismo" que é
o fundamento: o fundamento funda no abismo (MARCHART, 2009, p.
34 [Grifos nossos]).

A ideia de fundamento ausente, fundamento enquanto "abismo", não significa, insistimos, ausência de fundamento. Quando nos referimos ao fundamento sem fundamento, como na citação acima, a preposição "sem" deve ser compreendida não como uma ausência/vazio radical, mas como uma retirada, um "apagamento" da ideia forte de fundamento na qualidade de fundamento último.

Além da Heidegger, outra importante contribuição à crítica pósfundacionalista é a desconstrução derridiana. A leitura derridiana do descentramento da estrutura ocorre não por uma lógica de impossibilidade empírica, como se a impossibilidade de estabelecimentos de fundamentos estáveis à estrutura estivesse relacionada à multiplicidade de fundamentos possíveis. A problematização, portanto, não deve ser feita a partir da ideia 
excesso, mas pela noção de falta de um centro fixo que capture ou que seja preenchido por um fundamento.

O centro, na abordagem pós-estruturalista de Derrida (2002), deve ser entendido em termos de função: uma função, podemos assim dizer, organizativa da estrutura; uma função mais ou menos bem sucedida, sendo e não sendo centro:

[...] o centro encerra também o jogo que abre e torna possivel. Enquanto centro, é o ponto em que a substituição dos conteúdos, dos elementos, dos termos, já não é possível. No centro, é proibida a permuta ou a transformação dos elementos (que podem aliás ser estruturas compreendidas numa estrutura). Pelo menos sempre permaneceu interditada (e emprego propositalmente esta palavra). Sempre se pensou que o centro, por definição único, constituia, numa estrutura, exatamente aquilo que, comandando a estrutura, escapa à estruturalidade. Eis porque, para um pensamento clássico da estrutura, o centro pode ser dito, paradoxalmente, na estrutura e fora da estrutura. Está no centro da totalidade e contudo, dado que o centro não lhe pertence, a totalidade tem o seu centro noutro lugar. $\mathbf{O}$ centro não é o centro. O conceito de estrutura centrata - embora represente a própria coerência, a condição da episteme como filosofia ou como ciência - é contraditoriamente coerente. E como sempre, a coerência na contradição exprime a força de um desejo. $\mathbf{O}$ conceito de estrutura centrada é com efeito o conceito de um jogo fundado, constituido a partir de uma imobilidade fundadora e de uma certeza tranquilizadora, ela própria subtraída ao jogo. A partir desta certeza, a angústia pode ser dominada, a qual nasce sempre de uma certa maneira de estar implicado no jogo, de ser apanhado no jogo, de ser como ser logo de início no jogo (DERRIDA, 2002, p. 230231. [Grifos nossos]).

Como uma função, o centro ou fundamento estruturante não é imutável; sua presença, enquanto uma existência real, é sempre já marcada pela ausência, pelo vazio uma ausência estrutural que desconstrói ${ }^{12}$ a possibilidade de uma existência real, de um ponto de plena verdade, de um fundamento último à estrutura sem desconsiderar a própria discussão sobre os fundamentos ${ }^{13}$. Ou seja, essa desconstrução não significa um "giro para

\footnotetext{
12 A expressão é aqui usada no sentido da desconstrução derridiana em sua crítica à metafisica ocidental. A discussão sobre a desconstrução, um "quase conceito" apresentado pela primeira vez em Gramatologia, perpassa vários textos de Derrida em seu embate com o pensamento filosófico hegemônico de seu tempo. De uma forma mais ampla, a noção de desconstrução surge como uma "hipótese" contrária às teses de fechamento dos sentidos como "fonte de explicação" sedimentada pela metafisica da presença - dissemos hipótese devido ao cuidado que Derrida evidencia em não buscar "conceitos fechados", por isso "quase-conceito". Isso não significa passar de "um lado para o outro" a partir de uma simples substituição de preceitos, ou "destruição" do pensamento filosófico. A discussão de Derrida parte dos próprios discursos do pensamento ocidental para modificar e deslocar a própria ordem conceitual; uma mudança de enfoque e não uma mudança absoluta. Além de "Gramatologia" (1973), as obras "Margens da filosofia" (1991) e "A escritura e a diferença" (2002) fornecem uma ampla discussão sobre a noção de desconstrução.

13 Para um aprofundamento desta discussão em Derrida, conferir Ipar (2016).
} 
fora" da discussão sobre fundamentos e sim uma negação de fundamentos últimos. Mas essa falta é, ela mesma, constitutiva.

É importante perceber que a falta constitutiva indica duas coisas: em primeiro lugar, a impossibilidade de um centro fundante, de um fundamento último, logo, a abertura para possibilidades contingenciais de estabelecimentos de fundamentos parciais que cumpram a função de centro. Em segundo lugar, que nenhum desses fundamentos parciais podem, jamais, cumprir a função de centro de modo definitivo. Aqui devemos destacar algumas dimensões politicas dessas reflexões.

A proposta de fundamentos ausentes leva a consequências radicais no próprio campo político-filosófico. Isto porque, os fundamentos parciais não existem por si mesmos, eles são constituídos no campo das relações sociais e políticas. Dessa forma, o pós-fundacionalismo abre espaço para a construção de uma ontologia da política, mais especificamente, uma ontologia cuja política sobredetermina toda e qualquer posição epistemológica e não se subordina a nenhuma dimensão filosófica (MARCHART, 2009).

Partindo da perspectiva pós-fundacional, propomos adentrar em uma reflexão sobre a compreensão do mundo e do social a partir das contribuições de Ernesto Laclau (2000). A proposta desenvolvida pelo Autor tem a intenção de mostrar como a ruptura radical com a epistemologia do fundamento tem consequências significativas para entendermos a nossa realidade social. Tendo por base a reflexão de que os fundamentos sociais estão sempre fadados ao fracasso, , Laclau destaca a ideia de "impossibilidade da sociedade", referindo-se à impossibilidade de pensarmos a sociedade como um elemento inteligivel e permanente, como algo dado pela força do tempo, ou como possibilidade de alcançarmos um momento de uma sociedade uníssona, enquanto uma unidade fundamental de sentido.

$\mathrm{Na}$ leitura laclauniana, a sociedade, enquanto uma realidadetotalidade objetiva (fundamento final), só se constitui como resultado da sedimentação ${ }^{14}$ de fixações parciais e sobredeterminadas de sentidos (LACLAU;

\footnotetext{
14 A ideia de sedimentação, aqui utilizada, encontra-se na reflexão de Laclau (2000; 2014) a partir de Husserl. A noção de sedimentação, em Husserl, pode ser entendida como a rotinização e esquecimento das origens dos sentidos originais - para o aprofundamento dessa questão, ver Husserl (2009; 1989; 2008). Essa noção está diretamente relacionada à de reativação, entendida como retorno à situação
} 
MOUFFE, 2015; LACLAU, 2000; 2014). Ou seja, quando ela surge como uma realidade objetiva, com aparência de fundamento final (totalidade), é devido ao efeito da sedimentação de sentidos enquanto tal e não sua condição ontológica. Assim sendo, não estaríamos de fato diante de um fundamento, mas de um efeito da estrutura que se mostra permanente quando na verdade está apenas estabelecida de modo temporário, ainda que possa se mantêr por mil anos.

Por mais bem-sucedido que seja um discurso no processo de sedimentação (hegemonização), ele sempre carregará consigo as marcas de sua radical contingência: o momento de fundamentação, o momento do estabelecimento de um fundamento, evidencia a exclusão de alternativas, isto é, algo foi fundamentado, instituído, em detrimento de outro. Dessa forma, o social já não é pensado com um "jogo fechado", nunca se instaurará como uma realidade finalmente estabelecida, mas como resultado de um projeto hegemônico.

Por esse leitura pós-fundacionalista, o social deixa de ser percebido como uma "totalidade fundante que se apresenta a si mesma como um objeto inteligivel do "conhecimento"' (LACLAU, 2000, p. 104):

[...] hoje em dia tendemos a aceitar a infinitude do social, quer dizer, o fato de que todo sistema estrutural é limitado, que está sempre rodeado por um "excesso de sentido" que ele é incapaz de dominar e que, em consequência, a "sociedade" como objeto unitário e inteligivel que funda seus processos parciais, é uma impossibilidade [...]. O social não é tão somente o infinito jogo das diferenças. É também o intento de limitar este jogo, de domesticar a infinitude, de abarcá-la dentro da finitude de uma ordem. Mas esta ordem - ou estrutura - já não representa a forma de uma essência subjacente do social; é, ao contrário, o intento de atuar sobre o "social", de hegemonizá-lo (LACLAU, 2000, p. 104-105).

O princípio da impossibilidade de totalização do social, ou a impossibilidade de fundamentos últimos, pode levar a dois sentimentos radicalmente opostos. Pode levar à angústia da incerteza ou ao otimismo do

originária de significação. Na retomada laclauniana dessas categorias, a ideia de sedimentação, ainda muito próxima de Husserl - a única diferença, assim entendemos, é a dimensão politica que ganha com Laclau - é compreendida, em linhas gerais, como o "momento de uma situação de hegemonia", momento em que a luta por significação do social atinge um determinado sucesso que consegue ocultar o caráter radicalmente contingencial da instituição do social. Já a ideia de reativação, em Laclau (2000; 2014), não significa, como em Husserl, um movimento transcendental de retorno à situação originária, ao "da autoexistência original", mas de desconstrução do caráter objetivo de toda tentativa de sedimentação do social. O que Laclau busca destacar é que esse momento da "significação-primeira" já evidencia, em si mesmo, o caráter contingente de todo ato de decisão. Ou seja, no pensamento laclauniano não há espaço para um retorno à "evidência original" a la Husserl; e sim perceber que esse momento, um momento de fundamentação, evidencia a exclusão de alternativas: algo foi fundamentado, instituído, em detrimento de outro. 
jogo. A angústia seria causada pela "incerteza da existência inequívoca de uma archè ou de um telos. (...) [Ela é o findar] da tentativa de dominar o futuro, de tranquilizar-se com o porvir, de caminhar longe do Abgrund, de ser como ser logo de início no jogo" (MENDONÇA; LINHARES; BARROS, 2016, p.177). Dito de outro modo, não há um fundamento fora do jogo que defina o jogo previamente. Mas é esta mesma abertura que abre a liberdade infinita de criação dos seres humanos, desatando um campo radical de possibilidades extremamente importantes para as ciências sociais: por um lado, o mundo passa a ser compreendido como menos dado e qualquer sedimentação parcial depende das próprias construções sociais, e, por outro, as estruturas passam a ser compreendidas levando em consideração seu caráter radicalmente contingente, sempre diante das possibilidades de modificações mais ou menos radicais.

Em sintese, na inexistência de um fiador universal, o mundo social torna-se uma criação humana sujeita a todas as suas contingências. $\mathrm{Na}$ impossibilidade de solicitar ajuda externa para resolver os problemas da humanidade, ou de aceitar qualquer solução que venha de fora dela, restanos apenas tomá-los e resolvê-los com nossas próprias ideias. Estamos sozinhos, mas podemos ser arquitetos da sociedade, dentro de nossas próprias limitações.

\section{Considerações finais}

Ao longo do artigo, buscamos traçar as linhas gerais das bases do debate pós-fundacionalista, evidenciando aspectos histórico-filosóficos que envolvem seu surgimento, autores-chave, como Heidegger e Derrida, autores contemporâneos que buscam clarear o debate no campo das ciências sociais, notadamente Marchart (2009), Mendonça e Rodrigues (2014) e Mendonça, Linhares e Barros (2016), bem como especificar a distinção entre fundacionalismo, anti-fundacionalismo e pós-fundacionalismo.

Neste contexto ainda incipiente, a partir do qual o debate pósfundacionalista emerge como uma abordagem apta a reconfigurar e trazer à tona críticas relevantes a diferentes perspectivas teóricas existencialistas, esperamos ter contribuído para clarear alguns aspectos que envolvem esta 
abordagem, oferecendo ao leitor as linhas gerais sobre as quais este debate se desenvolve e, mais do que chegar a conclusões propriamente ditas, esperamos ter propiciado reflexões e questionamentos para um aprofundamento acerca desta perspectiva epistemológica.

Dentre outras importantes questões que se abrem com a crítica pósfundacional, não só no campo discursivo das ciências sociais, o ponto que nos parece mais importante está na compreensão do mundo como um eterno devir construído politicamente. Não seria exagero argumentar que o pensamento pós-fundacional pode ser visto como um movimento de expurgar das ciências humanas sua crença mítica de uma resolução final dos problemas da humanidade e a aceitação de nossa finitude histórica.

Dessa forma, a desconstrução da perspectiva fundacionalista e a abertura para uma contingência de fundamentos, precários e parciais, possibilita uma nova dimensão epistemológica capaz de propiciar a produção de conhecimento a partir de um espaço de dissolução das certezas, de múltiplas possibilidades, introduzindo uma nova percepção aos estudos das ciências sociais e humanas.

\section{Referências}

ABBAGNANO, Nicola. Dicionário de filosofia. $5^{\mathrm{a}}$ ed. São Paulo: Martins Fontes, 2007.

BURDZINSKI , Júlio César. Os problemas do fundacionismo. Kriterion: Revista de Filosofia. Vol. 48, $\mathrm{n}^{\circ}$. 115, 2007. Belo Horizonte. Disponível em:<http://www.scielo.br/pdf/kr/v48n115/a0748115.pdf>. Acesso em: 31 ago. 2017.

BUTLER, Judith P; SCOTT, Joan W. Feminists theorize the political. New York: Routledge, 1992.

CAPRA, Fritjof. O ponto de mutação. São Paulo: Círculo do Livro, 1972.

DELEUZE, Gilles. Em que se pode reconhecer o estruturalismo. História da filosofia-ideias, doutrinas, v. 8, 1972.

DERRIDA, Jacques. Gramatologia. São Paulo: Editora da Universidade de São Paulo, 1973.

Margens da filosofia. Campinas: Papirus, 1991. 
A escritura e a diferença. $3^{a}$ Ed. São Paulo: Editora Perspectiva, 2002.

DOSSE, François. História do Estruturalismo, v. 1: O campo do signo, 19451966. São Paulo: Ensaio; Campinas, SP: Editora da Universidade Estadual de Campinas, 1993.

FIANCO, Cristiane. O coerentismo de Bonjour: uma leitura fundacional. 179 p. 2011. Tese. Doutorado em Filosofia. Universidade Federal do Rio Grande do Norte.

HEIDEGGER, Martin. O Principio do Fundamento. Lisboa: Instituto Piaget, 1999.

HESSEN, Johannes. Teoria do Conhecimento. São Paulo: Martins Fontes, 2000.

HUSSERL, Edmund. A ingenuidade da ciência. Revista Scientiæ Studia, São Paulo, v. 7, n. 4, 2009, p. 659-670. Disponivel em:<http://www.scielo.br/pdf/ss/v7n4/a08v7n4.pdf>. Acesso em: 31 ago. 2017.

The Origin of Geometry, by Edmund Husserl. Trad. David Carr. In: DERRIDA, Jacques. Edmund Husserl's Origin of geometry: an introduction. Lincoln: University of Nebraska Press, 1989, p. 155-180.

La crisis de las ciencias europeas y la fenomenologia trascendental. Buenos Aires: Prometeo Libros, 2008.

IPAR, María Cecilia. Pensando em um horizonte epistemológico pósfundacional: a contribuição da teoria politica de Ernesto Laclau. VI Seminário Discente da Pós-Graduação em Ciência Política da USP. São Paulo, 2016. Disponivel em: <

conferencias.fflch.usp.br/sdpscp/VIsemDCP/paper/download/1632/247>. . Acesso em: 05 de jul. de 2019.

KETZER, Patrícia. Fundacionalismo: da tradição às teorias moderadas. Revista de Filosofia Argumentos, Ano 3, $\mathrm{n}^{\circ}$. 5, 2011. Disponível em:<http:/ /www.periodicos.ufc.br/argumentos/article/view/18990/29709> . Acesso em: 31 ago. 2017.

LACLAU, Ernesto. Nuevas reflexiones sobre la revolución de nuestro tiempo. Buenos Aires, 2a Ed., Editora Nueva Visión, 2000.

Los fundamentos retóricos de la sociedad. Buenos Aires: Fondo de Cultura Económica, 2014.

LACLAU, Ernesto; MOUFFE, Chantal. Hegemonia e estratégia socialista: por uma política democrática radical. São Paulo: Intermeios, 2015. 
MARCHART, Oliver. El pensamiento politico postfundacional. La diferencia politica en Nancy, Lefort, Badiou y Laclau. Buenos Aires, Fondo de Cultura Económica, 2009.

MENDONÇA, Daniel de; RODRIGUES, Léo Peixoto. Do estruturalismo ao Pósestruturalismo: entre fundamentar e desfundamentar. In: (Orgs), Pósestruturalismo e Teoria do Discurso: em torno de Ernesto Laclau. $2^{\text {a }}$ Ed., Porto Alegre. EDIPUCRS, 2014. p. 27-44.

MENDONÇA, Daniel; LINHARES, Bianca de Freitas; BARROS, Sebastián. O fundamento como "fundamento ausente" nas ciências sociais: Heidegger, Derrida e Laclau. Revista Sociologia, Porto Alegre, vol. 18, n. 41, 2016.

PESSANHA, José Américo Motta. Os pré-socráticos: vida e obra, 1978.

PETERS, Michael. Pós-estruturalismo e filosofia da diferença. Uma introdução. Belo Horizonte: Autêntica, 2000.

RODRIGUES, Léo Peixoto. O Estruturalismo Francês: aspectos históricos e epistemológicos. Ensaios de Sociologia e Política. Pelotas: UFPel, p. 133-175, 2010.

TAMAYO, Ruy Pérez. Existe o método cientifico? México: FCE, SEP, CONACyT, ECN, 2003.

WILLIAMS, James. Pós-estruturalismo. Petrópolis: Vozes, 2016. 